\title{
MPRA
}

Munich Personal RePEc Archive

\section{What Are the Carbon Emissions Elasticities for Income and Population? Bridging STIRPAT and EKC via robust heterogeneous panel estimates}

Liddle, Brantley

2015

Online at https://mpra.ub.uni-muenchen.de/61304/

MPRA Paper No. 61304, posted 14 Jan 2015 11:42 UTC 
What Are the Carbon Emissions Elasticities for Income and Population? Bridging STIRPAT and EKC via robust heterogeneous panel estimates

Brantley Liddle

Asia Pacific Energy Research Centre

Tokyo, Japan

Centre for Strategic Economic Studies, Victoria University

Melbourne, Australia

btliddle@alum.mit.edu

\begin{abstract}
Knowledge of the carbon emissions elasticities of income and population is important both for climate change policy/negotiations and for generating projections of carbon emissions. However, previous estimations of these elasticities using the well-known STIRPAT framework have produced such wide-ranging estimates that they add little insight. This paper presents estimates of the STIRPAT model that address that shortcoming, as well as the issues of cross-sectional dependence, heterogeneity, and the nonlinear transformation of a potentially integrated variable, i.e., income. Among the findings are that the carbon emissions elasticity of income is highly robust; and that the income elasticity for OECD countries is less than one, and likely less than the non-OECD country income elasticity, which is not significantly different from one. By contrast, the carbon emissions elasticity of population is not robust; however, that elasticity is likely not statistically significantly different from one for either OECD or non-OECD countries. Lastly, the heterogeneous estimators were exploited to reject a Carbon Kuznets Curve: while the country-specific income elasticities declined over observed average income-levels, the trend line had a slight U-shape.
\end{abstract}

Keywords: Carbon Kuznets Curves; Kaya identity; population and environment; nonstationary panels; cross sectional dependence; nonlinearities in environment and development.

Acknowledgements

The Pesaran (2004) CD test, the Pesaran (2006) common correlated effects mean group estimator, and the Eberhardt and Teal (2010) augmented mean group estimator were developed for STATA by Markus Eberhardt. The Pesaran (2007) panel unit root test was developed for STATA by Piotr Lewandowski. The final version benefited from comments by anonymous reviewers and the participants of a workshop organized by Brian O Neill at the National Center for Atmospheric Research, Boulder, CO in 2012.

Published in Global Environmental Change (2015) Vol. 31, pp. 62-73. DOI: 10.1016/j.gloenvcha.2014.10.016 


\section{Introduction and background}

Improved understanding of the carbon emissions elasticities of income and population is important both for climate change policy/negotiations and for generating projections of emissions. Indeed, the Kaya Identityみwhich treats total carbon emissions as a product of population GDP per capita, energy use per unit of GDP, and carbon emissions per unit of energy consumedみplays a key role in the Intergovernmental Panel on Climate Change estimates of future carbon emissions (Kaya 1990). This paper uses the Kaya/STIRPAT framework to determine what are the carbon emissions elasticities for income and population and whether those elasticities differ across development/income or population levels. The paper considers two econometric estimation methodsみthe Pesaran (2006) common correlated effects mean group estimator (CMG) and the Eberhardt and Teal (2010) augmented mean group estimator (AMG)み that address important (but often neglected) time-series cross-section (TSCS) issues:

nonstationarity, cross-sectional dependence, and heterogeneity. Furthermore, the paper addresses an additional important empirical issue particular to environment-development researchみthe nonlinear transformation of potentially integrated variables (see Wagner 2008 and Stern 2010 for previous treatments).

In addition to providing a critique of STIRPAT (Stochastic Impacts by Regression on Population, Affluence, and Technology) modeling, this paper bridges the STIRPAT literature with other socio-economic models of environmental impact that place the dependent variable in per capita termsみe.g., Environmental Kuznets Curve (EKC). That bridge is established by demonstrating that best practice suggests assuming the population elasticity is unity since estimations of the carbon emissions elasticity of population are: (i) not robust, (ii) typically not statistically significantly different from one, and (iii) do not vary systematically according to 
either income or population size. By contrast, the estimations reported here demonstrate that the carbon emissions elasticity of income are: (i) highly robust, (ii) significantly less than one (but positive) for OECD countries, and (iii) significantly larger for non-OECD countries than for OECD countries (but not different from significantly one for non-OECD countries). Also, the heterogeneous nature of the estimators considered was exploited to show that those income elasticities fall with average income but do not become negative.

Much discussion and research on national differences in the influence of population and of development/consumption (typically represented by GDP per capita) on key environmental indicators like carbon emissions are based on: (i) the IPAT equation (introduced by Ehrlich and Holdren 1971 and Commoner et al. 1971)みwhich decomposed aggregate environmental impacts (I) into contributions from population growth $(\mathrm{P})$, growth in per capita income or consumption (as measures of affluence, A), and changes in technology (T); and (ii) its econometric progeny, coined STIRPAT by Dietz and Rosa (1997). In general, the STIRPAT model is:

$$
I_{i t}=a P_{i t}^{b} A_{i t}^{c} T_{i t}{ }^{d} e_{i t}
$$

where the subscript $i$ denotes cross-sectional units (e.g., countries), $t$ denotes time period, the constant $a$ and exponents $b, c$, and $d$ are to be estimated, and $e$ is the residual error term.

Since Equation 1 is linear in log form, the estimated exponents can be thought of as elasticities (i.e., they reflect how much a percentage change in an independent variable causes a percentage change in the dependent variable.) Also, the $T$ term is often treated like an intensity of use variable and sometimes modeled as a combination of log-linear factors. Furthermore, Equation 1 is no longer an accounting identity whose right and left side dimensions must balance, but a potentially flexible framework for testing hypothesesみsuch as (i) whether elasticities differ across development levels; (ii) whether population or GDP has a greater 
marginal impact on the environment; and (iii) whether population elasticity is different from unity, i.e., whether population or impact/emissions grow faster.

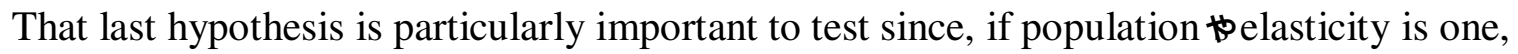
then population as an independent variable could be removed (from Equation 1) via division. Hence, the dependent variable would be in per capita terms, and the STIRPAT model would collapse into a framework similar to those used in nearly all other socio-economic investigations of emissions/energy consumption, e.g., the EKC literature (Dinda 2004 and Stern 2004 provided somewhat early reviews of this vast literature). The EKC literature seeks to determine whether there is an inverted-U relationship between GDP per capita and emissions or other environmental impact measure per capita. When the dependent variable is carbon emissions per capita, these studies are sometimes referred to as estimating Carbon Kuznets Curves or CKC (Iwata et al. 2011 and 2012 are recent examples). The EKC/CKC literature posits that pollution first rises with income and then falls after some threshold level of income/development is reached (Liddle 2013a presents a detailed review/explanation of the differences between the STIRPAT model and other socio-economic models/literatures like the EKC and energy-GDP causality).

Empirical studies of the EKC/CKC typically take the following form:

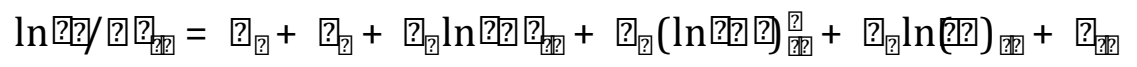

where $\alpha$ and $\gamma$ are the cross-sectional and time fixed effects, respectively, and $Z$ is a vector of other drivers that is sometimes consideredみsimilar to $T$ in Equation 1. Hence, the primary difference between the STIRPAT and EKC/CKC frameworks (i.e., between Equations 1 and 2) is that the EKC effectively assumes that population converts the dependent variable into per capita terms. An EKC/CKC between emissions per capita and income is said to exist if the coefficient ? $?_{\text {g }}$ is statistically significant and positive, 
while the coefficient $?_{\text {? }}$ is statistically significant and negative. (Liddle 2004 and Richmand and Kaufmann 2006 argued that if the corresponding turning point occurs outside the sample range, the estimated relationship is more like a semi-log or log-log one than an inverted-U; however, many EKC analyses do not even report implied turning points, and so it is not clear how widely accepted this interpretation is.)

More recently, a literature has emerged that attempts to bridge the CKC and energy-GDP causality literatures by adding energy consumption as an explanatory variable to the typical CKC model (e.g., Apergis and Payne 2009 and 2010; and Lean and Smyth 2010). Itkonen (2012) critiqued this new literature and called its model emissions-energy-output (EEO). Itkonen described the EEO model (for the single country case) as:

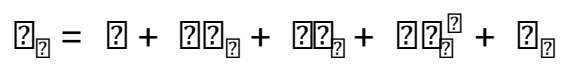

where $C$ is carbon dioxide emissions per capita, $E$ is total energy use per capita, $Y$ is real GDP per capita, and $u$ is an error term.

In addition to addressing nonstationarity, cross-sectional dependence, and heterogeneity, the current paper provides a bridge between the STIRPAT and EKC/CKC/EEO literatures. That bridge is constructed by determining whether population elasticity should be considered to be different from unity, and by exploiting heterogeneous estimators to address possible nonlinearitiesみthus, avoiding the statistical pitfall of nonlinear transformations of nonstationary variables. Further, the lessons learned here about econometric estimation methods should be useful to other modelersみ11 of the 17 STIRPAT studies listed in Table 1 were published in 2010 or later. (Yet, there are many more, recent studies applying the STIRPAT framework that are not listed in Table 1 because they considered different dependent variables, were not crossnational, and/or analyzed city-based/regional data rather than national-level data.) Furthermore, 
the EKC/CKC/EEO models continue to be popularみItkonen (2012) cited 16 EEO studies, of which only two were published prior to 2009 (and, for example, Baek and Kim 2013; Saboori and Sulaiman 2013 used the EEO model but were published after Itkonen).

2. Brief literature review and important empirical issues

The cross-national, inter-temporal studies applying the STIRPAT formulation to carbon emissions typically found that both population and income/affluence are significant drivers (see Table 1). Furthermore, most studies have found that population has a greater environmental impact (i.e., elasticity) than affluence (e.g., Dietz and Rosa 1997; Shi 2003; Cole and Neumayer 2004; Martinez-Zarzoso et al. 2007; Liddle and Lung 2010). However, these STIRPAT analyses have produced a wide range of income and population elasticity estimatesみfrom 0.15 to 2.50 for income and from 0.69 to 2.75 (with several statistically insignificant findings) for population. Moreover, in answering the question, む’ population やelasticity significantly different from one,め those studies have produced highly inconsistent results. For example, Cole and Neumayer (2004) found population $\$$ elasticity to be statistically indistinguishable from unity (thus, a $1 \%$ increase in population caused an approximate $1 \%$ increase in emissions). By contrast Shi (2003) estimated a particularly high elasticity for populationみbetween 1.4 and 1.6 for all countries samples; when Shi separated countries by income groups, the elasticity for high income countries was 0.8 , whereas the elasticity for middle and low income countries ranged from 1.4 to 2.0. Similarly, Martinez-Zarzoso et al. (2007) estimated a statistically insignificant population elasticity for old EU members, but an elasticity of 2.7 for recent EU accession countries. Table 1 suggests several reasons for this substantial variation: different datasets, different additional variables, and, perhaps most important, whether and how nonstationarity and heterogeneity were addressed. 
Table 1

\subsection{Stationarity}

Most variables used in STIRPAT analyses are stock (population) or stock-related variables (GDP, emissions, and energy consumption, which are influenced by stocks like population and physical capital); as such, those variables are highly trending and quite possibly nonstationaryみi.e., their mean, variance, and/or covariance with other variables changes over time. For example, in the energy economics literature a number of researchers have found variables like GDP per capita, energy consumption, and carbon emissions to be nonstationary in levels but stationary in first differences for panels of developed and developing countries (e.g., Apergis and Payne 2009 and 2010; Lean and Smyth 2010; and Liddle 2013b).

When ordinary least squares (OLS) regressions are performed on time-series (or on timeseries cross-section) variables that are not stationary, then measures like R-squared and tstatistics are unreliable, and there is a serious risk of the estimated relationships being spurious (Kao 1999; Beck 2008). Yet, several STIRPAT studies that employ annual times-series crosssection data have been unconcerned with the stationarity issue (see Table 1). (Indeed, Cole and Neumayer 2004 hypothesized that the much higher elasticity estimated in Shi 2003 may be spurious because of that paper $\$$ use of untreated, nonstationary data.) Most of the STIRPAT studies that have addressed stationarity in their data have done so via first differences (e.g., Cole and Neumayer 2004; and Martinez-Zarzoso et al. 2007). Although first-differencing often transforms nonstationary variables into stationary ones, first-differencing means that the model is a short-run (rather than a long-run) model, and that the estimated coefficients reflect how percentage changes in the growth rate of independent variables relate to percentage changes in the growth rate of the dependent variable. By contrast, the recent CKC literature (e.g., Iwata et 
al. 2011 and 2012) and the broader energy-GDP literature (which includes both EEO and energyGDP causality analyses) have estimated long run elasticities using methods that address nonstationarity.

\subsection{Cross-sectional dependence}

Recently, the TSCS econometric theory literature has turned its attention toward testing for and correcting cross-sectional dependence. For variables like GDP per capita and carbon emissions, cross-sectional dependence is expected because of, for example, regional and macroeconomic linkages that manifest themselves through (i) common global shocks, like the oil crises in the 1970s or the global financial crisis from 2007 onwards; (ii) shared institutions like the World Trade Organization, International Monetary Fund, or Kyoto Protocol; or (iii) local spillover effects between countries or regions. These shocks or institutions can be thought of as omitted variables, and are likely to be correlated with the regressors (Sarafidis and Wansbeek 2012). When the errors of panel regressions are cross-sectionally correlated, standard estimation methods can produce inconsistent parameter estimates and incorrect inferences (Kapetanios et al. 2011). Yet, Sadorsky (2014) is the only other STIRPAT analysis that employs methods to estimate long-run coefficients that are demonstrated to be robust to cross-sectional correlation, and perhaps only Wagner (2008), Stern (2010), and Mazzanti and Musolesi (2013) have performed such estimations in the panel EKC/CKC literature. Indeed, even the broader energyGDP literature typically has not estimated panel elasticities robust to cross-sectional correlation; known exceptions are Belke et al. (2011), Liddle (2013b), Sadorsky (2013), and Liddle and Lung (2013). 


\subsection{Heterogeneity and nonlinearities}

Heterogeneity, when considered, is typically addressed by splitting the panel along income lines (e.g., Poumanyvong and Kaneko 2010); indeed, nearly all STIRPAT studies have employed pooled estimators that otherwise assume the population-environment (or STIRPAT) relationship is the same for each country analyzed. By contrast, the estimators used in Liddle (2011 and 2013a) allow for a high degree of heterogeneity in the panel(s); hence, besides producing consistent point estimates of the panel sample means, those estimators provide country-specific estimates of all parameters accompanied by efficient standard normal errors. Indeed, Liddle (2011) demonstrated a substantial variation in individual STIRPAT elasticity estimations among OECD countries. And if one mistakenly assumes that the parameters are homogeneous (when the true coefficients of a dynamic panel in fact are heterogeneous), then all of the parameter estimates of the panel will be inconsistent (Pesaran and Smith 1995). The recent CKC and EEO literatures are mixed regarding the use of long run heterogeneous estimators; e.g., Apergis and Payne (2009 and 2010) and Lean and Smyth (2010) allowed for heterogeneity, while Iwata et al. (2011 and 2012) did not.

The EKC/CKC literature has hypothesized that the emissions-income relationship may vary across income/development levels; similarly, the environmental/emissions impact of population could change with either development (income) level or population size. That question of nonlinear relationships often is addressed by including a squared term in regressions and testing whether the coefficient for that squared term is negative and statistically significant. However, if the variables of interest (e.g., GDP per capita, population) are nonstationary or $I(1)$ variablesみas previous studies reported above as well as the tests reported below indicate they likely areみthen regressions involving nonlinear transformations of such integrated $(I(1))$ 
variables could be spurious, and their significance tests invalid (Bradford et al. 2005). (A variable is said to be integrated of order $d$, written $I(d)$, if it must be differenced $d$ times to be made stationary. Thus, a stationary variable is integrated of order zero, i.e., $I(0)$, and a variable that must be differenced once to become stationary is integrated of order one or $I(1)$.)

Wagner (2008) further argued that all previous EKC analyses that used panel data failed to account for both cross-sectional dependence and the nonlinear transformation of integrated GDP per capita. Relatedly, Itkonen (2012) argued that the nonlinearity of the CKC model (irrespective of order of integration issues) is incompatible with the vector autoregression (VAR) models used in the EEO literature; and hence, VAR models with such transformed regressors produce unreliable estimates.

Also, that polynomial model/regression does not allow for the possibility that elasticities are significantly different across development levels but still positive. Liddle (2013a) motivated the use of income-based panels to avoid this nonlinear transformation of a nonstationary variable while determining whether income effects differed across development/income levels. As will be discussed further below, we will exploit the heterogeneous estimators to determine whether GDP per capita $\ggg$ or population $\$$ impact is nonlinear.

3. Model, data, and methods

In addition to the usual independent variables of population and income/affluence, we consider two technology or intensity-type variables that are variations on two variables from the Kaya Identity: the carbon intensity of energy and the energy intensity of GDP. As a proxy for the carbon intensity of energy, we consider the share of primary energy consumption from non-fossil fuels (i.e., geothermal, nuclear, hydro, and solar/wind), which was used in Liddle and Lung 
(2010). Rather than include the aggregate energy-GDP ratio (or energy intensity), we consider, as did Liddle and Lung (2010), a measure of industrial energy intensity.

National, aggregate carbon emissions are calculated from national, aggregate energy consumption; thus, for countries with carbon intensive energy sources, aggregate carbon emissions and aggregate energy intensity run the risk of being highly correlated by construction, and thus, inappropriate for regression analysis. By contrast, this measure of industrial energy intensityみconstructed as industrial energy consumption (from the International Energy Agency) divided by industrial output (in GDP terms) みis not highly correlated with national carbon emissions (see Table 2, which shows such correlations). In addition, industrial energy intensity measures both the size of industrial activity and the composition of such activity (i.e., the presence of particularly energy intensive sectors like iron and steel and aluminum smelting); thus, it is preferable to measures of economic structure, like manufacturing or industry share of GDP. Industry is a diverse sector with respect to energy intensity, as it ranges from iron and steel and chemicals to textiles and the manufacturing of computing, medical, precision, and optical instruments. Some of those more technology-intensive manufacturing sectors may be less energy intense than some service sectors like transport, hospitality, and hospitals. Also, as Liddle and Lung (2010) argued, just because the share of economic activity from manufacturing or industry has declined does not mean the level of such activity has fallen; and it is the level of activity that should influence the level of aggregate emissions.

Industrial energy intensity (IEI) and the share of primary energy consumption from nonfossil fuels (Sh $n f f)$ are drawn from the International Energy Agency (IEA). Population $(P)$, carbon emissions $(I)$, and real GDP per capita ( $A$, which is converted to USD via purchasing power parities) are also from the IEA. Thus, the (unbalanced) dataset consists of observations 
over 1971-2011 from 26 OECD countries and 54 non-OECD countries. Every country with data beginning in at least 1985 was included (variables relating to industry output and industry energy consumption are what most restricted dataset coverage), and, according to World Bank data, the included countries accounted for $86 \%$ and $91 \%$ of 2011 world population and GDP, respectively, and $80 \%$ of 2010 world carbon dioxide emissions. (Appendix A lists the countries considered.) Summary statistics and correlations are displayed in Table 2.

Table 2

Table 3 displays the results of the Pesaran (2004) CD test, which employs the correlation coefficients between the time-series for each panel member. The null hypothesis of crosssectional independence is rejected for each variable and for both panels; moreover, several of the absolute value mean correlation coefficients are very high. The Pesaran (2007) panel unit root test (CIPS) allows for cross-sectional dependence to be caused by a single (unobserved) common factor, and that test is valid for both unbalanced panels and panels in which the cross-sectional and time dimensions are of the same order of magnitude; the results of that test suggest that carbon emissions, affluence/income, industrial energy intensity, and population are I(1). (Unit root test results are discussed in Appendix B and shown in accompanying tables.)

Table 3

Two OLS-based, heterogeneous or mean group type estimators are considered; they first estimate each group/cross-section specific regression and then average the estimated coefficients across the groups/cross-sections (standard errors are constructed nonparametrically as described in Pesaran and Smith 1995). Hence, the equation analyzed is:

$$
\ln I_{i t}=\alpha_{i}+c_{i} \ln P_{i t}+d_{i} \ln A_{i t}+e_{i} \ln I E I_{i t}+f_{i} \ln S h n f f_{i t}+\varepsilon_{i t}
$$


where subscripts it denote the $i$ th cross-section and $t$ th time period. Again, the slope coefficients $\left(c_{i}, d_{i}, e_{i}\right.$, and $\left.d_{i}\right)$ are heterogeneous, and the constant $\alpha$ represents country-specific effects.

Both mean group estimators were specifically designed to address both stationarity and cross-sectional dependence/correlation in TSCS models: the Pesaran (2006) common correlated effects mean group estimator (CMG), and augmented mean group (AMG) estimator by Eberhardt and Teal (2010). The CMG estimator accounts for the presence of unobserved common factors by including in the regression cross-sectional averages of the dependent and independent variables. The AMG estimator accounts for cross-sectional dependence by including in the regression a common dynamic processみwhich is extracted from year dummy coefficients of a pooled regression in first differences. Both the $\mathrm{CMG}$ and $\mathrm{AMG}$ estimators are robust to nonstationary variables, whether cointegrated or not (Eberhardt and Teal 2010); thus, arguably, they do not require the pre-testing (neither to determine the existence of cointegration nor to confirm that all variables are of the same order of integration) that other heterogeneous, nonstationary panel estimators like Fully Modified OLS and Dynamic OLS require. Also, both the CMG and AMG estimators are robust to serial correlation (Pesaran 2006; Eberhardt and Teal 2010, respectively); and CMG-type estimators are robust to structural breaks (Kapetanios et al. 2011).

For diagnostics we run the Pesaran (2004) CD test on the residuals and report the mean absolute correlation coefficient to determine/measure the extent of cross-sectional dependence, and the Pesaran (2007) CIPS test to demonstrate that the residuals are I(0). Appendix Table C.1 displays elasticity results (and diagnostics) from several other popular TSCS estimators. The diagnostic results displayed in Table C.1 suggest that the CMG and AMG estimators are preferred (over the estimators in Table C.1) for addressing the statistical issues of concern here. 
(For discussion of several of the estimators in Appendix $\mathrm{C}$ and their results see the working paper version, Liddle 2012.) Lastly, the CMG and AMG estimators allow the inclusion of individual, country-specific time trends. The decision on whether to include such trends was based on two factors: (i) the share of cross-sections for which such trends were statistically significant at the 5\% level; and (ii) whether the inclusion of such trends substantially improved the panel cross-sectional dependence diagnostics. However, the full regression results (each estimation with and without individual time trends) are contained in a supplemental file.

4. Results and discussion

Table 4 displays the regression results from the two heterogeneous panel estimators (CMG and AMG) for an all countries panel and with the sample divided between the 26 OECD countries and the 54 non-OECD countries. For all three sets of regressions all the coefficients have the expected signs and are statistically significant. In addition, the diagnostics are good: the residuals always are stationary, and either cross-sectional independence in the residuals cannot be rejected or cross-sectional dependence is mitigated (small mean correlation coefficients).

The all countries panel results suggest that population $\$$ elasticity may be significantly larger than that of income $\$$ and significantly greater than unity. Yet, dividing the sample into two panels may be justified since, in comparing the confidence intervals for the two panels (OECD vs. non-OECD countries), the income elasticity for carbon emissions, when estimated via $\mathrm{CMG}$, is greater for non-OECD countries than for OECD countriesみevidence of an income saturation effect. (For the other three variables, the elasticities are not statistically significantly different between the two development groups.) 
Table 4

For OECD countries, the elasticity for income is significantly less than one, whereas, the elasticity for population is not different from one at the $5 \%$ level of statistical significance. For non-OECD countries, the long-run elasticity for income is not significantly different from one for the CMG estimator. The elasticity for population is, as for the all countries panel, greater than one on average; yet, only for the AMG estimator is the elasticity for population statistically significantly greater than one or possibly statistically significantly greater than the elasticity for income.

\subsection{Sensitivity/robustness over time}

To test whether the elasticities for affluence and population are robust over time, the two estimators (CMG and AMG) are performed on 12 different time spans for both of the panels (OECD and non-OECD countries)みa total of 48 regressions (see Appendix D for the time spans considered). To avoid the problem of the panels differing substantially across time spans, only countries with data beginning in 1971 were considered. The elasticity estimations for income and population from those 48 panel regressions are displayed in Appendix D; we summarize those results here. The panel elasticities for affluence were highly robust: the average panel coefficient (from the different time-span regressions) was similar to that shown in Table 4; the coefficients were always statistically significant; and for the OECD panel, the affluence coefficient was statistically different (smaller) than unity in all but three of the 24 regressionsみby contrast, for non-OECD countries, the coefficient was different from unity in only six of 24 regressions.

On the other hand, the population elasticity was not robust. For the CMG estimator (and both the OECD and non-OECD panels), the population elasticity was statistically significant in only four of 24 regressions. For the 24 regressions run with the AMG estimator, the population 
elasticity was statistically significant in 21 of them; however, it was never statistically different from unity for the OECD panel and was only statistically significantly different from unity (larger) in three of 12 regressions for the non-OECD panel. (The sensitivity analysisみdisplayed in Appendix Dみrevealed no evidence that the size, significance, or sign of the population elasticity may have changed over-time, e.g., from 1970-1990 to 1990-2006.)

\subsection{Nonlinearities in population and income elasticities}

In addition to the possibility that the income and population elasticities could be different at different levels of development (i.e., in OECD vs. non-OECD countries), these elasticities could change as the level of income or population changes. Thus, we consider whether the individual country income/population elasticity estimates vary according to the level of income/population by plotting those elasticity estimates against the individual country average income/population for the whole sample period (rather than by including in the regression equation nonlinear transformations of these $I(1)$ variables).

\subsubsection{Nonlinearities in population elasticities}

Figure 1 shows the country-specific population elasticities (from the AMG estimator) plotted against the individual country average GDP per capita for the sample period (for all countries). (The results from the CMG estimator were essentially the same.) Here, there appears no relationship (R-squared is 0.005$)$ みthe population elasticities do not vary meaningfully according to income.

\section{Figure 1}

Similarly, there was no relationship between the individual country population elasticity and country average population size. Figure 2 displays the country-specific population elasticities plotted against the country average population for the sample period (for all 
countries). The resulting trend line (also shown in the figure) is (nearly) horizontal, and the Rsquared is less than 0.01 .

\section{Figure 2}

4.2.2 Carbon emissions per capita estimates and nonlinearities in income elasticities

It seems reasonable to estimate a model with carbon emissions per capita as the dependent variable (and thus no independent population variable) given (i) what we have just shownみthat the population elasticity does not vary meaningfully according to income level or population size; (ii) the previous discussion of the sensitivity resultsみthat the population elasticity was significantly different from unity in only about $10 \%$ of the regressions; and (iii) the O Teill et al. (2012) argument that, む入 if all other influences on emissions are controlled for, and indirect effects of population on emissions through other variables are excluded, then population can only act as a scale factor[,] and its elasticity should therefore be $1 . \bigotimes$ Furthermore, converting the dependent variable into per capita terms makes the transformed model comparable to the models used in nearly all other socio-economic investigations of emissions/energy consumptionみe.g., EKC/CKC and EEO models. Table 5 displays the results of such carbon emissions per capita estimates.

Table 5

All of the diagnostics are good: the residuals always are stationary, and cross-sectional independence in the residuals can never be rejected. Also, the estimates of the remaining variables are very similar to those estimates shown in Table 4. Again, there is evidence of an income saturation effect, and thus, a justification to separate dataset into (at least) two panels (OECD vs. non-OECD countries). Indeed, in comparing the confidence intervals for the two panels, there is arguably stronger evidence (than displayed in Table 4) that the income elasticity 
for carbon emissions is greater for non-OECD countries than for OECD countries (although the AMG estimations are different only at the $10 \%$ significance level).

Lastly, Figure 3 shows the country-specific income elasticity estimates (from the model with carbon emissions in per capita terms) plotted against the individual country average GDP per capita for the sample period (for all countries). (The AMG estimator was used, and again, the results from the $\mathrm{CMG}$ estimation were essentially the same.) The figure also indicates the quadratic trend line (which has an R-squared of 0.34). The income elasticities fell throughout the average income range. While two countries (Belgium and Sweden) estimated statistically significant negative elasticities, there is no evidence that a panel income elasticity would become negativeみindeed, the trend line has a slight U-shaped pattern; thus, a CKC, where carbon emissions would eventually decline with income, is rejected. (When the CMG estimator was used, no countries had significant, negative estimations for the income elasticity.) Hence, using different methods than both Wagner (2008)みde-factored regressionsみand Stern (2010)みthe between estimatorみused, we come to the same conclusion they did: when both cross-sectional dependence is addressed and the nonlinear transformation of potentially integrated GDP per capita is avoided, there is no Carbon Kuznets Curve.

Figure 3

\section{Conclusions}

The carbon emissions elasticity of affluence/income appears quite robust. For developed/OECD countries income elasticity is significantly less than one; for less developed/non-OECD countries income elasticity is significantly larger than that of those more developed countries, but not significantly different from oneみi.e., carbon emissions and income are more or less proportional for non-OECD countries. Thus, as countries develop the carbon 
intensity of income/consumption falls, but higher levels of income lead to higher levels of carbon emissions. In other words, an inverted-U relationship with income, or an Environmental/Carbon Kuznets Curve, is likely for carbon emissions divided by GDP, but not for carbon emissions per capita. (Indeed, the trend line shown in Figure 3 had a slight U-shape.) In order to test for an EKC/CKC relationship, we exploited the heterogeneous nature of our estimatorsみa method that avoided two related statistical issues that plagued nearly all previous (EKC/CKC and EEO) analyses: (i) the nonlinear transformation of a potentially integrated variable (noted and addressed in Wagner 2008, and addressed in Stern 2010); and (ii) the nonlinear transformation of a regressor in a VAR model (noted in Itkonen 2012). Furthermore, it could be argued that the heterogeneous-based approach used here has certain advantages: (i) it is simpler than de-factored regressions (used in Wagner 2008); and (ii) it is more robust to the presence of difference stationary regressors, does not preclude the possibility of cointegration modeling, and (relatedly) takes fuller account of all time-variant information unlike the between estimator (used in Stern 2010). Moreover, the approach used hereみin contrast to the polynomial of income model/approachみexplicitly allows for the possibility that elasticities are significantly different across development levels but still always positive.

In contrast to income, the carbon emissions elasticity of population is not at all robust. The only statements we can make with much confidence are: (i) that the population elasticity is likely not statistically significantly different from oneみeven though its estimated mean is often greater than one (the accompanying confidence intervals are typically very large); and (ii) that the population elasticity does not vary systematically according to either income/development level or aggregate population size. Perhaps, modelers should expect population to function only as a scaling factor; or alternatively, modelers may want to use the population variable as a 
measure to capture むther influencesめor missing variables by research designみto compare urban vs. rural populations, for example. Yet, as demonstrated here, even when one addresses the time-series properties of population via the most current TSCS estimation methods, the population elasticity still is not robust (when different time spans were examined).

Hence, given (i) the likelihood that the elasticity of population is not different from unity; (ii) the lack of robustness in estimating the population elasticity (even when state-of-the-art TSCS methods are used); and (iii) the difficulty in establishing population $\$$ integration properties in the absence of very long time dimensioned data, should modelers take the Њめout of STIRPAT (i.e., divide the dependent variable by population)? Removing population as an explanatory variable likely would remove an important source of the cross-analyses robustness problem. Indeed, STIRPAT analyses that have employed cross-sectional data only (no time varying observations) have estimated population elasticites not significantly different from one or at least very near one (see Table 1 in O Teill et al. 2012); this phenomenon is true even for studies considering different dependent variables (e.g., fuelwood consumption by Knight and Rosa 2012), or different units/scales of analysis (e.g., US county-level data in Roberts 2011; international city-based data in Liddle 2013c). And converting most or all of the variables into per capita (or percentage/share terms as in urbanization and age structure) also mitigates heteroscedasticity-related issues. Per capita measured variables result in differences (estimation errors) between countriesみlike Switzerland and United States or China and Taiwanみthat are much smaller than such differences resulting from the use of aggregate measurements. Finally, converting the dependent variable into per capita terms would make the transformed model comparable to the models used in nearly all other socio-economic investigations of emissions/energy consumption (e.g., EKC). 


\section{References}

Apergis, N. and Payne, J. 2009. $\mathrm{CO}_{2}$ emissions, energy usage, and output in Central America. Energy Policy, 37, 3282-3289.

Apergis, N. and Payne, J. 2010. The emissions, energy consumption, and growth nexus: Evidence from the commonwealth of independent states. Energy Policy, 38, 650-655.

Baek, J. and Kim, H-S. 2013. Is economic growth good or bad for the environment? Empirical evidence from Korea. Energy Economics, 36, 744-749.

Beck, N. 2008. Time-SeriesみCross-Section Methods. In Oxford Handbook of Political Methodology. Box-Steffensmeier, J., Brady, H., and Collier, D. (eds.). New York: Oxford University Press.

Belke, A. Dobnik, F., and Dreger, C. 2011. Energy consumption and economic growth: New insights into the cointegration relationship. Energy Economics, 33(5), 782-789.

Bradford, D., Fender, R., Shore, S., and Wagner, M. (2005) "The Environmental Kuznets Curve: Exploring a Fresh Specification," Contributions to Economic Analysis \& Policy: Vol. 4(1), Article 5.

Cole, M.A. and Neumayer, E. 2004. Examining the impact of demographic factors on air pollution. Population \& Environment 26(1), 5-21.

Commoner, B., Corr, M., Stamler, P.J. 1971. The causes of pollution. Environment 13(3), 2-19.

Dietz, T. and Rosa, E.A. 1997. Effects of population and affluence on CO2 emissions. Proceedings of the National Academy of Sciences - USA 94, 175-179.

Dinda, S. 2004. Environmental Kuznets curve hypothesis: A survey. Ecological Economics 49, 431-455.

Eberhardt, M. and Teal, F. (2010) Productivity Analysis in Global Manufacturing Production, Economics Series Working Papers 515, University of Oxford, Department of Economics.

Ehrlich, P.R., Holdren, J. 1971. Impact of population growth. Science 171, 1212-1217.

Fan, Y., Liu, L-C., Wu, G., and Wei. Y-M.. (2006). Analyzing impact factors of $\mathrm{CO}_{2}$ emissions using the STIRPAT model. Environmental Impact Assessment Review, 26, 377-395.

Itkonen, J. 2012. Problems estimating the carbon Kuznets curve. Energy, 39, 274-280.

Iwata, H., Okada, K., and Samreth, S. 2011. A note on the environmental Kuznets curve for $\mathrm{CO}_{2}$ : A pooled mean group approach. Applied Energy, 88, 1986-1996. 
Iwata, H., Okada, K., and Samreth, S. 2012. Empirical study on the determinants of $\mathrm{CO}_{2}$ emissions: evidence from OECD countries. Applied Economics, 44, 3513-3519.

Jorgenson, A. and Clark, B. 2010. Assessing the temporal stability of the population/environment relationship in comparative perspective: a cross-national panel study of carbon dioxide emissions, 1960-2005. Population and Environment, 32, 27-41.

Jorgenson, A. and Clark, B. 2012. Are the economy and the environment decoupling? A comparative international study, 1960-2005. American Journal of Sociology 118(1), 1-44.

Jorgenson, A., Rice, J., and Clark, B. 2010. Cities, slums, and energy consumption in less developed countries, 1990 to 2005. Organization and Environment 23(2), 189-204.

Kao, C. 1999. Spurious regression and residual-based tests for cointegration in panel data. Journal of Econometrics, 65(1), 9-15.

Kapetanios, G., Pesaran, M.H., and Yamagata, T. 2011. Panels with non-stationary multifactor error structures. Journal of Econometrics 160, 326-348.

Kaya, Y. 1990. Impacts of carbon dioxide emission control on GNP growth: interpretation of proposed scenarios. Paper presented to the IPCC Energy and Industry Subgroup, Response Strategies Working Group, Paris.

Knight, K. And Rosa, E. 2012. Household dynamics and fuelwood consumption in developing countries: a cross-national analysis. Population and Environment 33, 365-378.

Knight, K., Rosa, E., and Schor, J. 2013. Could working less reduce pressures on the environment? A cross-national panel analysis of OECD countries, 1970-2007. Global Environmental Change, 23, 691-700.

Lean, H-H. and Smyth, R. 2010. $\mathrm{CO}_{2}$ emissions, electricity consumption and output in ASEAN. Applied Energy, 87, 1858-1864.

Liddle, B. 2004. Demographic dynamics and per capita environmental impact: using panel regressions and household decompositions to examine population and transport. Population and Environment, 26, 23-39.

Liddle, B. (2011) Consumption-driven environmental impact and age-structure change in OECD countries: A cointegration-STIRPAT analysis. Demographic Research, Vol. 24, pp. 749-770.

Liddle, B. 2012 What are the carbon emissions elasticities for income and population? A robustness exercise employing the STIRPAT framework. USAEE Working Paper No. 12-135. Available via SSRN. http://ssrn.com/abstract=2162222. 
Liddle, B. 2013a.Population, Affluence, and Environmental Impact Across Development: Evidence from Panel Cointegration Modeling. Environmental Modeling and Software, Vol. 40, 255-266.

Liddle, B. 2013b. The energy, economic growth, urbanization nexus across development: Evidence from heterogeneous panel estimates robust to cross-sectional dependence. The Energy Journal 34(2), 223-244.

Liddle, B. 2013c. Urban density and climate change: A STIRPAT analysis using city-level data. Journal of Transport Geography 28, 22-29.

Liddle, B. and Lung, S. 2010. Age Structure, Urbanization, and Climate Change in Developed Countries: Revisiting STIRPAT for Disaggregated Population and Consumption-Related Environmental Impacts. Population and Environment, 31, 317-343.

Liddle, B. and Lung, S. 2013. The long-run causal relationship between transport energy consumption and GDP: Evidence from heterogeneous panel methods robust to cross-sectional dependence. Economic Letters, 121, 524-527.

Mazzanti, M. and Musolesi, A. 2013. The heterogeneity of carbon Kuznets curves for advanced countries: comparing homogeneous, heterogeneous and shrinkage/Bayesian estimators. Applied Economics, 45, 3827-3842.

Martinez-Zarzoso, I., Bengochea-Morancho, A., and Morales-Lage, R. 2007. The impact of population on $\mathrm{CO} 2$ emissions: evidence from European countries. Environmental and Resource Economics 38, 497-512.

Martinez-Zarzoso, I. and Maruotti, A. 2011. The impact of urbanization on $\mathrm{CO}_{2}$ emissions: Evidence from developing countries. Ecological Economics, 70, pp. 1344-1353.

Menz, T. and Welsch, H. 2012. Population aging and carbon emissions in OECD countries: Accounting for life-cycle and cohort effects. Energy Economics, 34, pp.842-849.

O Teill, B., Liddle, B., Jiang, L., Smith, K., Pachauri, S., Dalton, M., and Fuchs, R. 2012. Demographic change and carbon dioxide emissions. The Lancet, 380, 157-164.

Pesaran, M. (2004) General Diagnostic Tests for Cross Section Dependence in Panels' IZA Discussion Paper No. 1240.

Pesaran, M. (2006) 'Estimation and inference in large heterogeneous panels with a multifactor error structure.' Econometrica, Vol. 74(4): pp.967-1012.

Pesaran, M. 2007. A simple panel unit root test in the presence of cross-section dependence. Journal of Applied Econometrics, 22: 265-312. 
Pesaran, M. and Smith, R. 1995. Estimating long-run relationships from dynamic heterogeneous panel., Journal of Econometrics, 68, 79-113.

Poumanyvong, P. and Kaneko, S. 2010. Does urbanization lead to less energy use and lower $\mathrm{CO}_{2}$ emissions? A cross-country analysis. Ecological Economics. 70, 434-444.

Richmond, A. and Kaufmann, R. 2006. Is there a turning point in the relationship between income and energy use and/or carbon emissions? Ecological Economics 56, 176-189.

Roberts, T. 2011. Applying the STIRPAT model in a post-Fordist landscape: Can a traditional econometric model work at the local level? Applied Geography 31, 731-739.

Saboori, B. and Sulaiman, J. 2013. CO2 emissions, energy consumption and economic growth in Association of Southeast Asian Nations (ASEAN) countries: A cointegration approach. Energy, $55,813-822$.

Sadorsky, P. 2013. Do urbanization and industrialization affect energy intensity in developing countries? Energy Economics, 37, 52-59.

Sadorsky, P. 2014. The effect of urbanization on $\mathrm{CO}_{2}$ emissions in emerging countries. Energy Economics, 41, 147-153.

Sarafidis, V. and Wansbeek, T. 2012. Cross-sectional dependence in panel data analysis. Econometric Reviews, 31(5), 483-531.

Shi, A. (2003). The impact of population pressure on global carbon dioxide emissions, 19751996: evidence from pooled cross-country data. Ecological Economics, 44, 29-42.

Stern, D. 2004. The rise and fall of the environmental Kuznets curve. World Development, 32(8), 1419-1439.

Stern, D. 2010. Between estimates of the emissions-income elasticity. Ecological Economics, 69, 2173-2182.

Wagner, Martin. 2008. the carbon Kuznets curve: A cloudy picture emitted by bad econometrics? ぬResource and Energy Economics 30, 3: 388-408.

York, R. (2007). Demographic trends and energy consumption in European Union Nations, 1960-2025. Social Science Research, 36, 855-872.

York, R. 2008. De-carbonization in former Soviet republics, 1992-2000: The ecological consequences of de-modernization. Social Problems, 55 (3), 370-390.

Zhu, H.-M., You, W.-H., and Zeng, Z.-f. 2012. Urbanization and $\mathrm{CO}_{2}$ emissions: A semiparametric panel data analysis. Economics Letters, 117, 848-850. 
Table 1. Cross-national, inter-temporal STIRPAT studies estimating the drivers of $\mathrm{CO}_{2}$ emissions. Values indicate elasticities of emissions with respect to changes in GDP per capita (income) and population size.

\begin{tabular}{|c|c|c|c|c|c|}
\hline Study & Affluence/income & Population size & Additional variables & Data structure & $\begin{array}{l}\text { Addressed } \\
\text { nonstationarity? }\end{array}$ \\
\hline Sadorsky, 2014 & 1.14 (SR); 0.90 (LR) & 1.33 (SR); 2.52 (LR) & Energy-GDP ratio & $\begin{array}{l}\text { TSCS: } 16 \text { emerging } \\
\text { countries, 1971-2009 }\end{array}$ & $\begin{array}{l}\text { Yes, via AMG } \\
\text { estimator }\end{array}$ \\
\hline $\begin{array}{l}\text { Knight et al., } \\
2013^{\text {a }}\end{array}$ & 0.59 & 2.25 & Urbanization & $\begin{array}{l}\text { TSCS: } 29 \text { OECD countries, } \\
\text { 1970-2007 }\end{array}$ & $\begin{array}{l}\text { Yes, via first } \\
\text { difference model }\end{array}$ \\
\hline Liddle, 2013c ${ }^{c}$ & $\begin{array}{l}1.00 \text { (overall); } 0.44 \\
(\mathrm{HI}) ; 1.00(\mathrm{MI}) ; 0.97 \\
(\mathrm{LI})\end{array}$ & $\begin{array}{l}1.05 \text { (overall); } 0.68 \text { (HI); } \\
0.86 \text { (MI); } 0.70(\mathrm{LI})\end{array}$ & & $\begin{array}{l}\text { TSCS: } 23 \mathrm{HI}, 25 \mathrm{MI}, \& 37 \mathrm{LI} \\
\text { countries, 1971-2007 }\end{array}$ & $\begin{array}{l}\text { Yes, via panel } \\
\text { cointegration \& } \\
\text { panel FMOLS }\end{array}$ \\
\hline Zhu et al., 2012 & 1.12 & 0.79 & $\begin{array}{l}\text { Energy consumption; } \\
\text { urbanization }\end{array}$ & $\begin{array}{l}\text { TSCS: } 20 \text { non-OECD } \\
\text { countries, 1992-2008 }\end{array}$ & $\begin{array}{l}\text { Yes, via first } \\
\text { difference model }\end{array}$ \\
\hline $\begin{array}{l}\text { Jorgenson \& } \\
\text { Clark, } 2012\end{array}$ & 0.93 & 1.55 & $\begin{array}{l}\text { Urbanization; trade share of } \\
\text { GDP }\end{array}$ & $\begin{array}{l}\text { Panel: } 86 \text { countries, } 1960- \\
2005 \text { at } 5-y r \text { intervals }\end{array}$ & $\begin{array}{l}\text { Mitigated via panel } \\
\text { data structure }\end{array}$ \\
\hline $\begin{array}{l}\text { Menz \& Welsch, } \\
2012^{a}\end{array}$ & 0.36 & 0.78 & $\begin{array}{l}\text { Age structure; birth cohort; } \\
\text { share of electricity from coal; } \\
\text { urbanization }\end{array}$ & $\begin{array}{l}\text { Panel: } 26 \text { OECD countries; } \\
\text { 1960-2005 at 5-yr } \\
\text { intervals }\end{array}$ & $\begin{array}{l}\text { Mitigated via panel } \\
\text { data structure }\end{array}$ \\
\hline $\begin{array}{l}\text { Martinez- } \\
\text { Zarzoso \& } \\
\text { Maruotti, 2011 }\end{array}$ & 0.72 & NS & $\begin{array}{l}\text { Energy-GDP ratio; GDP share } \\
\text { for industry; urbanization }\end{array}$ & $\begin{array}{l}\text { TSCS: } 88 \text { non-OECD } \\
\text { countries, } 1975-2003\end{array}$ & $\begin{array}{l}\text { Yes, via difference } \\
\text { model }^{\text {b }}\end{array}$ \\
\hline Liddle, $2011^{c}$ & 1.06 & 2.35 & Age structure & $\begin{array}{l}\text { TSCS: } 22 \text { OECD countries, } \\
\text { 1960-2007 }\end{array}$ & $\begin{array}{l}\text { Yes, via panel } \\
\text { cointegration \& } \\
\text { panel FMOLS }\end{array}$ \\
\hline $\begin{array}{l}\text { Poumanyvong } \\
\text { \& Kaneko, } 2010 \\
\text { a }\end{array}$ & $\begin{array}{l}1.08 \text { (overall); } 0.83 \\
\text { (HI); } 0.99(\mathrm{MI}) ; 2.50 \\
\text { (LI) }\end{array}$ & $\begin{array}{l}1.12 \text { (overall); } 1.12(\mathrm{HI}) ; \\
1.23 \text { (MI); } 1.75(\mathrm{LI})\end{array}$ & $\begin{array}{l}\text { Energy-GDP ratio; GDP share } \\
\text { for service \& industry; } \\
\text { urbanization }\end{array}$ & $\begin{array}{l}\text { TSCS: } 33 \mathrm{HI}, 43 \mathrm{MI} \text {, and } 23 \\
\text { LI countries, 1975-2005 }\end{array}$ & $\begin{array}{l}\text { Yes, via first } \\
\text { difference model }\end{array}$ \\
\hline $\begin{array}{l}\text { Jorgenson \& } \\
\text { Clark, } 2010^{a}\end{array}$ & $\begin{array}{l}0.65 \text { (overall); } 0.95 \\
\text { (OECD); } 0.64 \text { (non- } \\
\text { OECD) }\end{array}$ & $\begin{array}{l}1.43 \text { (overall); } 1.65 \text { (OECD); } \\
1.27 \text { (non-OECD) }\end{array}$ & $\begin{array}{l}\text { Trade as share of GDP; } \\
\text { urbanization }\end{array}$ & $\begin{array}{l}\text { Panel: } 22 \text { DC and } 64 \text { LDC; } \\
\text { 1960-2005 at 5-yr } \\
\text { intervals }\end{array}$ & $\begin{array}{l}\text { Yes, via first } \\
\text { difference model \& } \\
\text { panel structure }\end{array}$ \\
\hline $\begin{array}{l}\text { Jorgenson et al., } \\
2010^{\text {a e }}\end{array}$ & 0.33 & 0.70 & $\begin{array}{l}\text { Share population aged 15-64; } \\
\text { GDP share for manufacturing; } \\
\text { urbanization; share } \\
\text { population living in urban } \\
\text { slums }\end{array}$ & TSCS: 57 LDC, 1990-2005 & $\begin{array}{l}\text { Yes, via first } \\
\text { difference model }\end{array}$ \\
\hline $\begin{array}{l}\text { Liddle \& Lung, } \\
2010^{a}\end{array}$ & 0.57 & 0.69 & $\begin{array}{l}\text { Age structure; energy-GDP } \\
\text { ratio for industry; Share of }\end{array}$ & $\begin{array}{l}\text { Panel: } 17 \text { OECD countries, } \\
\text { 1960-2005 at 5-yr }\end{array}$ & $\begin{array}{l}\text { Mitigated via panel } \\
\text { data structure }\end{array}$ \\
\hline
\end{tabular}




\begin{tabular}{|c|c|c|c|c|c|}
\hline & & & $\begin{array}{l}\text { primary energy from nonfossil } \\
\text { fuels; urbanization }\end{array}$ & intervals & \\
\hline York, 2008 & 0.50 & 1.87 & $\begin{array}{l}\text { Aged dependency ratio; } \\
\text { Urbanization; FDI as share of } \\
\text { GDP; military personnel per } \\
1000\end{array}$ & TSCS: 15 FSR, 1992-2000 & No \\
\hline $\begin{array}{l}\text { Martinez- } \\
\text { Zarzoso et al., } \\
2007^{\text {a }}\end{array}$ & $\begin{array}{l}0.42 \text { (overall); } 0.15 \\
\text { (15 old EU); } 0.34 \text { (8 } \\
\text { new EU) }\end{array}$ & $\begin{array}{l}\text { NS (overall); } 0.71^{\mathrm{d}} \text { ( } 15 \text { old } \\
\text { EU); } 2.73 \text { ( } 8 \text { new EU) }\end{array}$ & $\begin{array}{l}\text { Energy-GDP ratio; GDP share } \\
\text { for industry }\end{array}$ & $\begin{array}{l}\text { TSCS: } 23 \text { EU countries, } \\
\text { 1975-1999 }\end{array}$ & $\begin{array}{l}\text { Yes, via first } \\
\text { difference model }\end{array}$ \\
\hline York, $2007^{\mathrm{e}}$ & 0.70 & 2.75 & $\begin{array}{l}\text { Share of old dependent } \\
\text { population; urbanization }\end{array}$ & $\begin{array}{l}\text { TSCS: } 14 \text { EU countries; } \\
\text { 1960-2000 }\end{array}$ & No \\
\hline Fan et al., $2006^{\dagger}$ & $\begin{array}{l}0.30 \text { (overall);0.54 } \\
\text { (HI); } 0.21 \text { (UMI); } 0.28 \\
\text { (LMI); } 0.33 \text { (LI) }\end{array}$ & $\begin{array}{l}0.68 \text { (overall); } 0.57 \text { (HI); } 0.33 \\
\text { (UMI); } 0.44 \text { (LMI); } 0.26 \text { (LI) }\end{array}$ & $\begin{array}{l}\text { Share population aged 15-64; } \\
\text { Energy-GDP ratio; } \\
\text { urbanization }\end{array}$ & $\begin{array}{l}\text { TSCS: } 218 \text { countries, } 1975- \\
2000\end{array}$ & No \\
\hline $\begin{array}{l}\text { Cole \& } \\
\text { Neumayer, } 2004 \\
\text { a }\end{array}$ & 0.89 & 0.98 & $\begin{array}{l}\text { Age structure; Average } \\
\text { household size; Energy-GDP } \\
\text { ratio; GDP share for } \\
\text { manufacturing; urbanization }\end{array}$ & $\begin{array}{l}\text { TSCS: } 86 \text { countries, 1975- } \\
1998\end{array}$ & $\begin{array}{l}\text { Yes, via first } \\
\text { difference model }\end{array}$ \\
\hline Shi, 2003 & 0.80 & $\begin{array}{l}0.83 \text { (HI); } 1.42 \text { (UMI); } 1.97 \\
\text { (LMI); } 1.58 \text { (LI) }\end{array}$ & $\begin{array}{l}\text { GDP share for manufacturing } \\
\text { \& service }\end{array}$ & $\begin{array}{l}\text { TSCS: } 88 \text { countries, } 1975- \\
1996\end{array}$ & No \\
\hline
\end{tabular}

Notes: ${ }^{a}$ estimations were performed in first differences or with a lagged dependent variable; and thus, those elasticities could be interpreted as short-run (as opposed to long-run). ${ }^{b}$ Martinez-Zarzoso \& Maruotti perform panel unit root tests that suggest the variables are panel I(0); however, as discussed in the text, this is a highly unusual result; and thus, we report their results from a difference generalized method of moments model. ${ }^{\mathrm{c}}$ dependent variable was $\mathrm{CO}_{2}$ emissions from all (domestic) transport activity. ${ }^{d}$ statistically significant at $p<0.10 .{ }^{e}$ dependent variable was total energy use. ${ }^{f}$ estimations performed via partial least squares; hence results may not be compatible with other studies.

TSCS: time-series cross-section. NS= not statistically significant at the $p<0.10$ level or higher. SR=short run. $L R=$ long run. AMG=augmented mean group. FMOLS=fully modified ordinary least squares. OECD=Organization for Economic Cooperation and Development; EU=European Union; FSR=former Soviet republics; $D C=$ developed countries; LDC=less developed countries; HI=high income; $\mathrm{Ml}=$ middle income; Ll=low income; UMI=upper-middle income; LMI=lower-middle income. 
Table 2. Summary statistics and correlations (all variables in natural logs).

\begin{tabular}{|c|c|c|c|c|c|}
\hline Variable & Obs & Mean & Std. dev. & Min. & Max. \\
\hline $\mathrm{CO}_{2}$ & 3280 & 3.37 & 2.05 & -1.66 & 8.98 \\
\hline A & 3280 & 8.64 & 1.27 & 5.48 & 11.21 \\
\hline Pop & 3280 & 16.67 & 1.49 & 12.25 & 21.02 \\
\hline IEI & 3144 & -2.21 & 0.83 & -6.55 & 0.49 \\
\hline Sh nff & 3277 & -3.47 & 1.65 & -9.24 & -0.18 \\
\hline Correlations & $\mathrm{CO}_{2}$ & $\mathbf{A}$ & Pop & IEI & Sh nff \\
\hline $\mathrm{CO}_{2}$ & 1 & & & & \\
\hline $\mathbf{A}$ & 0.519 & 1 & & & \\
\hline Pop & 0.648 & -0.235 & 1 & & \\
\hline IEI & 0.157 & -0.176 & 0.100 & 1 & \\
\hline Sh nff & 0.112 & 0.340 & -0.072 & -0.022 & 1 \\
\hline
\end{tabular}

Table 3. Cross-sectional dependence: Absolute value mean correlation coefficients and Pesaran (2004) CD test.

\begin{tabular}{lccccc}
\hline & \multicolumn{5}{c}{ Variables } \\
\cline { 2 - 6 } Panels & Log $\mathrm{CO}_{2}$ & Log A & Log Pop & Log IEI & Log Sh $\mathrm{n} f f$ \\
\hline OECD countries & 0.70 & 0.96 & 0.90 & 0.72 & 0.57 \\
$(\mathbf{2 6})$ & $\left(18.3^{*}\right)$ & $\left(108.1^{*}\right)$ & $\left(87.9^{*}\right)$ & $\left(51.5^{*}\right)$ & $\left(33.0^{*}\right)$ \\
\hline Non-OECD & 0.76 & 0.65 & 0.98 & 0.43 & 0.50 \\
countries (54) & $\left(134.5^{*}\right)$ & $\left(93.1^{*}\right)$ & $\left(209.3^{*}\right)$ & $\left(17.2^{*}\right)$ & $\left(29.0^{*}\right)$ \\
\hline
\end{tabular}

Notes: $\mathrm{CO}_{2}$ is aggregate carbon emissions; $\mathrm{A}$ is real GDP per capita; Pop is population; IEI is industry energy intensity; Sh nff is share of nonfossil fuels in primary energy. Absolute value mean correlation coefficient shown. CD-test statistic is in parentheses. Null hypothesis is crosssectional independence. Statistical significance indicated by $*<0.001$. 
Table 4. Heterogeneous panel STIRPAT estimations. Aggregate carbon emissions dependent variable. $95 \%$ confidence intervals in brackets.

\begin{tabular}{lcccccc}
\hline & \multicolumn{2}{c}{ All countries (80) } & \multicolumn{2}{c}{ OECD countries (26) } & \multicolumn{2}{c}{ Non-OECD countries (54) } \\
\hline & CMG & AMG & CMG & AMG & CMG & AMG \\
\cline { 2 - 7 } Log A & $0.81^{* *}$ & $0.87^{* *}$ & $0.58^{* *}$ & $0.71^{* *}$ & $0.89^{* *}$ & $0.83^{* *}$ \\
& {$[0.690 .93]$} & {$[0.740 .99]$} & {$[0.410 .75]$} & {$[0.580 .84]$} & {$[0.741 .04]$} & {$[0.710 .95]$} \\
Log Pop & $1.38^{*}$ & $1.85^{* *}$ & $0.81^{*}$ & $1.26^{* *}$ & $1.32^{* *}$ & $1.87^{* *}$ \\
& {$[0.981 .78]$} & {$[1.292 .41]$} & {$[0.031 .59]$} & {$[0.332 .20]$} & {$[0.951 .70]$} & {$[1.612 .15]$} \\
Log IEI & $0.18^{* *}$ & $0.18^{* *}$ & $0.17^{* *}$ & $0.16^{* *}$ & $0.17^{* *}$ & $0.19^{* *}$ \\
& {$[0.150 .22]$} & {$[0.140 .23]$} & {$[0.100 .24]$} & {$[0.090 .24]$} & {$[0.120 .21]$} & {$[0.130 .25]$} \\
Log sh nff & $-0.14^{* *}$ & $-0.13^{* *}$ & $-0.12^{* *}$ & $-0.13^{* *}$ & $-0.13^{* *}$ & $-0.13^{* *}$ \\
& {$[-0.17-0.10]$} & {$[-0.17-0.10]$} & {$[-0.16-0.07]$} & {$[-0.17-0.08]$} & {$[-0.17-0.09]$} & {$[-0.18-0.09]$} \\
Obs & & & & & & \\
RMSE & 3141 & 3141 & 1045 & 1045 & 2096 & 2096 \\
Order of & 0.054 & 0.064 & 0.030 & 0.036 & 0.063 & 0.081 \\
integration & $\mathrm{I}(0)$ & $\mathrm{I}(0)$ & $\mathrm{I}(0)$ & $\mathrm{I}(0)$ & $\mathrm{I}(0)$ & $\mathrm{I}(0)$ \\
Mean rho & & & & & & \\
CD (p) & 2.17 & 0.17 & 0.14 & 0.16 & 0.18 & 0.18 \\
\hline
\end{tabular}

Notes: A is real GDP per capita; Pop is population; IEI is industry energy intensity; sh nff is share of nonfossil fuels in primary energy. Obs is observations, and RMSE is the root mean squared error. $*$ and $* *$ indicate statistical significance at the $5 \%$ and $1 \%$ levels, respectively. Diagnostics: Order of integration of the residuals is determined from the Pesaran (2007) CIPS test: $\mathrm{I}(0)=$ stationary. Mean rho is the mean absolute correlation coefficient of the residuals from the Pesaran (2004) CD test. CD is the test statistic from that test along with the corresponding pvalue in parentheses. The null hypothesis is cross-sectional independence. 
Table 5. Heterogeneous panel estimations. Carbon emissions per capita dependent variable. 95\% confidence intervals in brackets.

\begin{tabular}{lcccc}
\hline & \multicolumn{2}{c}{ OECD countries (26) } & \multicolumn{2}{c}{ Non-OECD countries (54) } \\
\hline & \multicolumn{2}{c}{ CMG } & AMG & \multicolumn{2}{c}{ CMG } & AMG \\
\cline { 2 - 5 } $\log$ A & $0.57^{*}$ & $0.75^{*}$ & $0.97^{*}$ & $0.96^{*}$ \\
& {$[0.370 .77]$} & {$[0.610 .89]$} & {$[0.791 .14]$} & {$[0.831 .09]$} \\
Log IEI & $0.17^{*}$ & $0.16^{*}$ & $0.20^{*}$ & $0.20^{*}$ \\
& {$[0.100 .25]$} & {$[0.070 .25]$} & {$[0.140 .26]$} & {$[0.120 .28]$} \\
Log sh nff & $-0.12^{*}$ & $-0.13^{*}$ & $-0.13^{*}$ & $-0.12^{*}$ \\
& {$[-0.16-0.08]$} & {$[-0.18-0.09]$} & {$[-0.16-0.09]$} & {$[-0.17-0.07]$} \\
Obs & & & & \\
RMSE & 1045 & 1045 & 2096 & 2096 \\
Order of integration & 0.034 & 0.039 & 0.071 & 0.092 \\
Mean rho & $\mathrm{I}(0)$ & $\mathrm{I}(0)$ & $\mathrm{I}(0)$ & $\mathrm{I}(0)$ \\
CD (p) & 0.18 & 0.19 & 0.19 & 0.19 \\
\hline Notes: A & $-0.1(0.94)$ & $-1.3(0.20)$ & $1.4(0.15)$ & $0.9(0.35)$ \\
\hline
\end{tabular}

Notes: A is real GDP per capita; IEI is industry energy intensity; sh nff is share of nonfossil fuels in primary energy. Obs is observations, and RMSE is the root mean squared error. * indicates statistical significance at the $0.1 \%$ level.

Diagnostics: Order of integration of the residuals is determined from the Pesaran (2007) CIPS test: $\mathrm{I}(0)=$ stationary. Mean rho is the mean absolute correlation coefficient of the residuals from the Pesaran (2004) CD test. CD is the test statistic from that test along with the corresponding pvalue in parentheses. The null hypothesis is cross-sectional independence. 


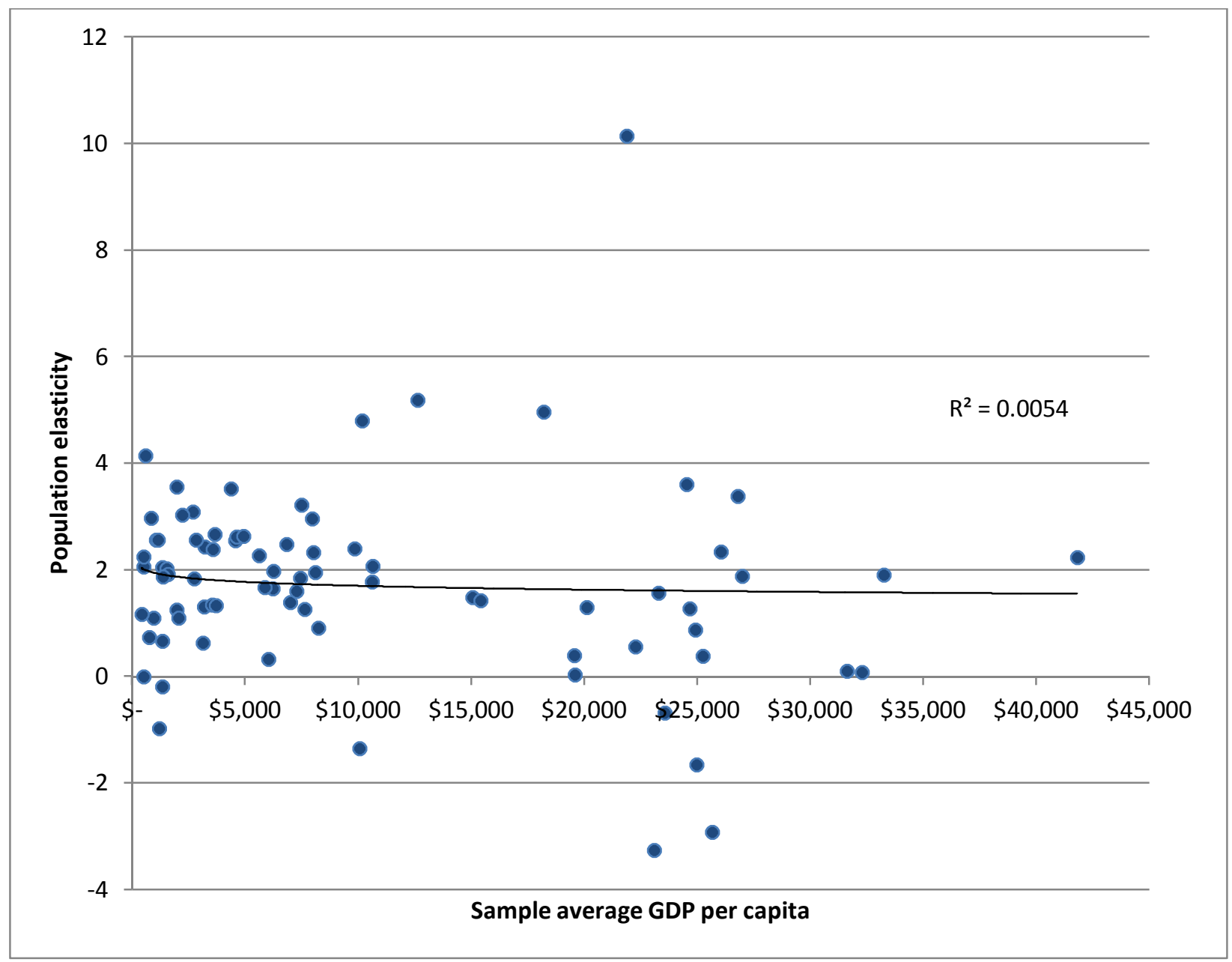

Figure 1. Individual country population elasticity estimates (from AMG) and the country average GDP per capita for the sample period (for all countries). Trend line and R-squared also shown. 


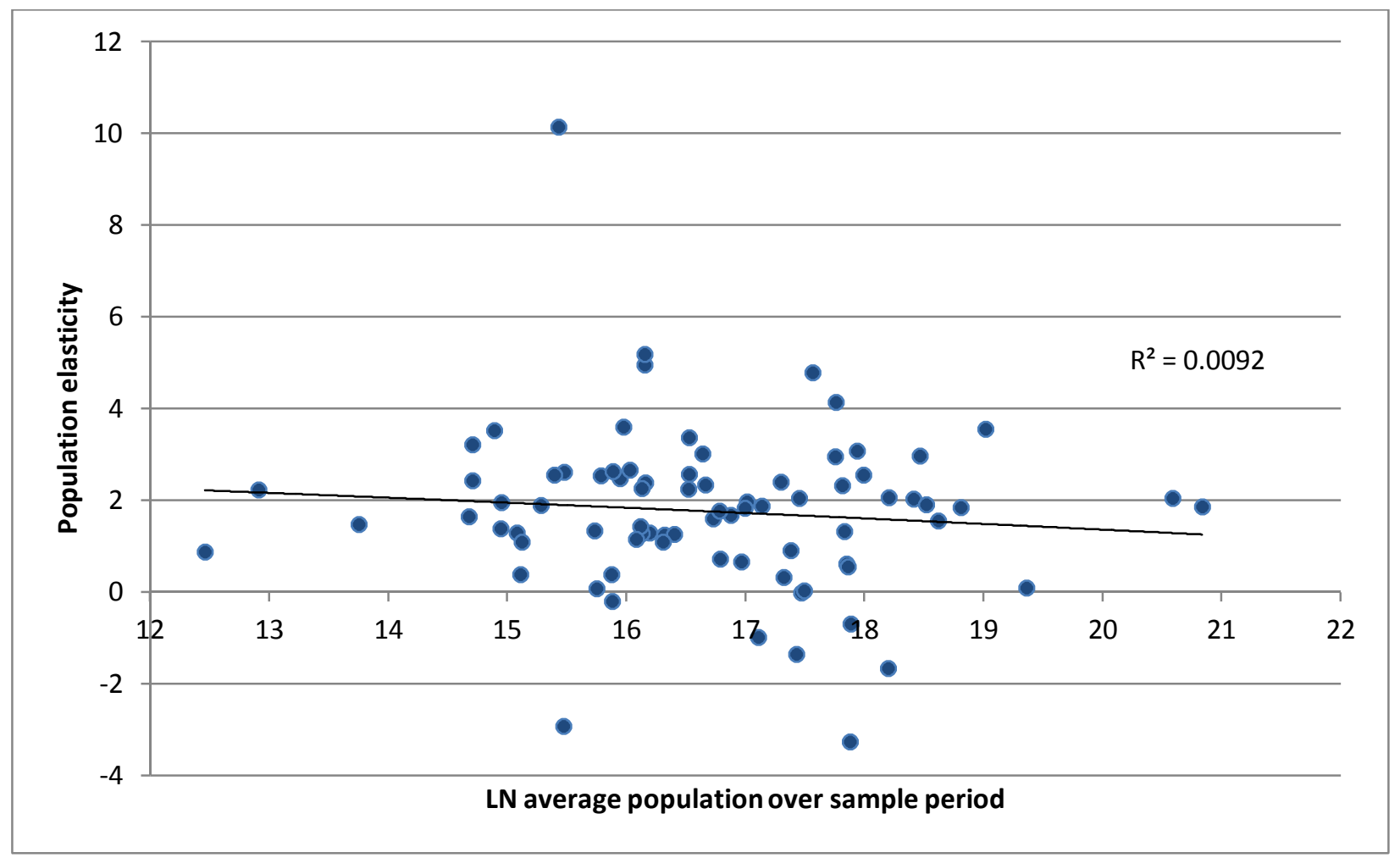

Figure 2. Individual country population elasticity estimates (from AMG) and the natural log of country average population for the sample period (for all countries). Trend line and R-squared also shown. 


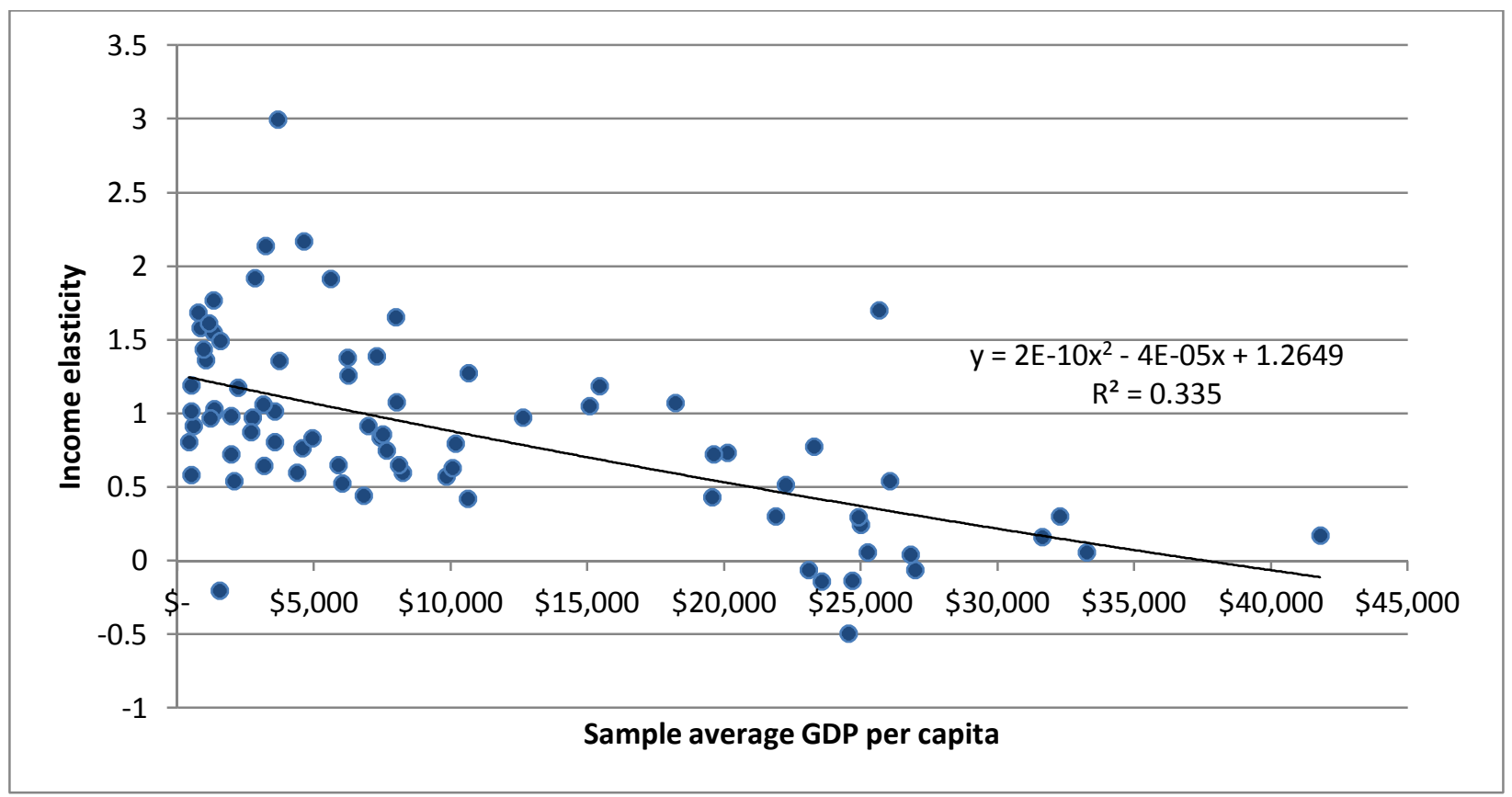

Figure 3. Individual country income elasticity estimates (from AMG) and the country average GDP per capita for the sample period (for all countries). Carbon emissions per capita is the dependent variable. Trend line, equation, and R-squared also shown. 
Appendix A. List of countries (by World Bank three letter code).

\begin{tabular}{lllcl}
\hline \multicolumn{2}{c}{ OECD (26) } & & Non-OECD (54) & \\
\hline AUS & IRL & AGO & EGY & NPL \\
AUT & ISL & ALB & ETH & PAK \\
BEL & ITA & ARG & GAB & PAN \\
CAN & JPN & BGD & GHA & PER \\
CHE & KOR & GGR & HND & SHL \\
DEU & LUX & BOL & IDN & SLV \\
DNK & NLD & BRA & IND & TGO \\
ESP & NOR & CHL & IRN & THA \\
FIN & NZL & CHN & JAM & TUN \\
FRA & POL & CIV & KEN & TUR \\
GBR & CRT & CMR & LKA & URY \\
GRC & COG & MAR & VEN \\
HUN & SWE & COL & MEX & VNM \\
& USA & CRI & MOZ & ZAF \\
& & CUB & MYS & ZAR \\
& & DOM & NGA & ZMB \\
& & DZA & ZWE
\end{tabular}


Appendix B. Unit root tests

Appendix Table B.1 displays the results of the Pesaran (2007) panel unit root test (CIPS). The null hypothesis of the test is nonstationarity; thus, if the null is rejected in levels, the series is assumed to be $I(0)$; however, if the null fails to reject when in levels, but is rejected when in first differences, the series is assumed to be $I(1)$. The CIPS test results suggest that carbon emissions, affluence/income, and industrial energy intensity are I(1); however, the results for population are ambiguousみdepending on the choice of lag structure and trend inclusion, it could be $\mathrm{I}(0)$ or $\mathrm{I}(1)$.

\section{Appendix Table B.1}

Yet, population is a classic stock variable: population in period $t$ is exactly equal to the population in period $t-1$ less the deaths, plus the births and net migration (that occurred over the intervening time). In other words, unlike for GDP, we do understand the むata generation process $\Varangle$ or population, and that process is the same everywhere. Unless the change in population (births and net migration less deaths) is equal to zero over time, population likely does not have a constant mean (i.e., is not stationary). Innovations to fertility and mortality rates (e.g., education of girls leading to changes in desired family size or wide-spread adoption of health/safety measures like hand-washing) do cause permanent changes; but after an adjustment period, we would expect fertility and mortality rates to be constant. Therefore, we expect population to be a I(1) variable, i.e., trending over time, but its change or first difference has a (nonzero) constant mean.

The problem in calculating population $\$$ order of integration (as demonstrated by the results in Appendix Table B.1) is likely a manifestation of the poor/limited power of unit root tests when the time dimension is relatively short. (Time-series econometricians consider 50 observations to be むshort. \$Hence, we create a long panel (1820-2008) consisting of 19 OECD 
countries via data compiled by Angus Madison

(http://www.ggdc.net/MADDISON/oriindex.htm). Now the CIPS test produces a highly robust result of $I(1)$. Appendix Table B.2 shows that with lags varying from zero to eight and with or without a trend in the regression, population is confirmed as a $I(1)$ variable at the highest levels of significance.

\section{Appendix Table B.2}

Appendix Table B.1. Pesaran (2007) panel unit root tests for 80 country sample.

\begin{tabular}{|c|c|c|c|c|c|c|}
\hline \multirow[b]{3}{*}{ No. lags } & \multicolumn{6}{|c|}{ Variables in Levels } \\
\hline & \multicolumn{3}{|c|}{ Constant w/o trend } & \multicolumn{3}{|c|}{ Constant w/ trend } \\
\hline & 1 & 2 & 3 & 1 & 2 & 3 \\
\hline Log Pop & 0.000 & 0.995 & 0.996 & 0.000 & 0.001 & 0.001 \\
\hline $\log \mathrm{CO}_{2}$ & 0.042 & 0.150 & 0.353 & 0.998 & 0.999 & 1.000 \\
\hline $\log A$ & 0.998 & 1.000 & 0.998 & 0.653 & 0.993 & 0.828 \\
\hline Log IEI & 0.068 & 0.896 & 0.778 & 0.620 & 0.999 & 0.999 \\
\hline \multirow[t]{2}{*}{ Log sh nff } & 0.000 & 0.000 & 0.070 & 0.000 & 0.000 & 0.033 \\
\hline & \multicolumn{6}{|c|}{ Variables in first differences } \\
\hline No. lags & 1 & 2 & 3 & 1 & 2 & 3 \\
\hline Log Pop & 0.000 & 0.000 & 0.000 & 0.000 & 0.000 & 0.000 \\
\hline $\log \mathrm{CO}_{2}$ & 0.000 & 0.000 & 0.000 & 0.000 & 0.000 & 0.000 \\
\hline $\log A$ & 0.000 & 0.000 & 0.000 & 0.000 & 0.000 & 0.000 \\
\hline Log IEI & 0.000 & 0.000 & 0.000 & 0.000 & 0.000 & 0.000 \\
\hline Log sh nff & 0.000 & 0.000 & 0.000 & 0.000 & 0.000 & 0.000 \\
\hline
\end{tabular}

Notes: P-values shown for null hypothesis of I(1). Pop is population. $\mathrm{CO}_{2}$ is aggregate carbon emissions; A is real GDP per capita; IEI is industry energy intensity; sh nff is share of nonfossil fuels in primary energy. 
Appendix Table B.2. Pesaran (2007) panel unit root tests for population of a panel of 19 OECD countries, 1820-2008.

\begin{tabular}{|c|c|c|c|c|c|c|}
\hline \multirow[b]{2}{*}{$\begin{array}{l}\text { Number of } \\
\text { lags }\end{array}$} & \multicolumn{3}{|c|}{ Constant $w / o$ trend } & \multicolumn{3}{|c|}{ Constant w/ trend } \\
\hline & level & $\begin{array}{c}\text { First } \\
\text { difference }\end{array}$ & conclusion & level & $\begin{array}{c}\text { First } \\
\text { difference }\end{array}$ & conclusion \\
\hline 0 & $\begin{array}{c}3.12 \\
(1.00)\end{array}$ & $\begin{array}{l}-15.55 \\
(0.00)\end{array}$ & $\mathrm{I}(1)$ & $\begin{array}{l}11.04 \\
(1.00)\end{array}$ & $\begin{array}{l}-15.80 \\
(0.00)\end{array}$ & $\mathrm{I}(1)$ \\
\hline 1 & $\begin{array}{c}1.44 \\
(0.92)\end{array}$ & $\begin{array}{r}-13.76 \\
(0.00)\end{array}$ & $\mathrm{I}(1)$ & $\begin{array}{c}6.15 \\
(1.00)\end{array}$ & $\begin{array}{r}-13.86 \\
(0.00)\end{array}$ & $\mathrm{I}(1)$ \\
\hline 2 & $\begin{array}{c}1.86 \\
(0.96)\end{array}$ & $\begin{array}{l}-10.76 \\
(0.00)\end{array}$ & $\mathrm{I}(1)$ & $\begin{array}{c}5.75 \\
(1.00)\end{array}$ & $\begin{array}{l}-10.32 \\
(0.00)\end{array}$ & $\mathrm{I}(1)$ \\
\hline 3 & $\begin{array}{c}1.52 \\
(0.94)\end{array}$ & $\begin{array}{l}-9.76 \\
(0.00)\end{array}$ & $\mathrm{I}(1)$ & $\begin{array}{c}5.35 \\
(1.00)\end{array}$ & $\begin{array}{l}-9.19 \\
(0.00)\end{array}$ & $\mathrm{I}(1)$ \\
\hline 4 & $\begin{array}{c}1.91 \\
(0.97)\end{array}$ & $\begin{array}{l}-7.72 \\
(0.00)\end{array}$ & $\mathrm{I}(1)$ & $\begin{array}{c}5.68 \\
(1.00)\end{array}$ & $\begin{array}{l}-7.00 \\
(0.00)\end{array}$ & $\mathrm{I}(1)$ \\
\hline 5 & $\begin{array}{c}1.58 \\
(0.94)\end{array}$ & $\begin{array}{l}-6.64 \\
(0.00)\end{array}$ & $\mathrm{I}(1)$ & $\begin{array}{c}5.11 \\
(1.00)\end{array}$ & $\begin{array}{l}-5.66 \\
(0.00)\end{array}$ & $\mathrm{I}(1)$ \\
\hline 6 & $\begin{array}{c}1.51 \\
(0.94)\end{array}$ & $\begin{array}{l}-5.16 \\
(0.00)\end{array}$ & $\mathrm{I}(1)$ & $\begin{array}{c}5.19 \\
(1.00)\end{array}$ & $\begin{array}{l}-3.93 \\
(0.00)\end{array}$ & $\mathrm{I}(1)$ \\
\hline 7 & $\begin{array}{c}1.16 \\
(0.88)\end{array}$ & $\begin{array}{l}-4.62 \\
(0.00)\end{array}$ & $\mathrm{I}(1)$ & $\begin{array}{c}4.89 \\
(1.00)\end{array}$ & $\begin{array}{l}-3.42 \\
(0.00)\end{array}$ & $\mathrm{I}(1)$ \\
\hline 8 & $\begin{array}{c}1.10 \\
(0.86)\end{array}$ & $\begin{array}{l}-3.71 \\
(0.00)\end{array}$ & $\mathrm{I}(1)$ & $\begin{array}{c}4.91 \\
(1.00)\end{array}$ & $\begin{array}{l}-2.44 \\
(0.01)\end{array}$ & $\mathrm{I}(1)$ \\
\hline
\end{tabular}

Notes: Pesaran (2007) Z-statistic with associated p-value (in parentheses) shown. Null hypothesis is the series is $\mathrm{I}(1)$.

Countries: Australia, Austria, Belgium, Denmark, Finland, France, Germany, Greece, Ireland, Italy, Japan, Netherlands, Norway, Portugal, Spain, Sweden, Switzerland, United Kingdom, and United States.

Data from http://www.ggdc.net/MADDISON/oriindex.htm. 
Appendix C: Additional time series, cross section estimators

POLS: $\quad$ Pooled OLS with time dummies

2FE:

Fixed effects with time dummies (two-way fixed effects)

2FE-LDV:

FE-Prais:

FD-OLS:

Fixed effects with lagged dependent variable and time dummies

P-FMOLS:

Prais-Winsten serial correlation correction with country and time dummies

OLS with variables in first differences and time dummies

Pooled version of Fully Modified OLS. FMOLS involves a semiparametric correction for serial correlation and endogeneity.

P-DOLS: $\quad$ Pooled version of Dynamic OLS. DOLS involves adding leads and lags of the first differences of the explanatory variables in order to address endogeneity and serial correlation. One lead and one lag of each are added.

MG-FMOLS: $\quad$ Mean group FMOLS, where the panel estimates are the average over the individual cross-section FMOLS estimates.

MG-DOLS: $\quad$ Mean group DOLS, where the panel estimates are the average over the individual cross-section DOLS estimates. One lead and one lag of each RHS variable and common time dummies were added. Performed by STATA command xtpedroni, which was developed by Timothy Neal.

P-FMOLS, P-DOLS, and MG-FMOLS were performed in EViews. In theory, FMOLS and DOLS require successful cointegration pretesting (not performed/shown). 
Appendix Table C.1. Additional STRIPAT estimations on 80 country sample. Aggregate carbon emissions dependent variable.

\begin{tabular}{|c|c|c|c|c|c|c|c|c|c|}
\hline & \multicolumn{7}{|c|}{ Pooled Estimators } & \multicolumn{2}{|c|}{ Heterogeneous Estimators } \\
\hline & POLS & 2FE & 2FE-LDV & FE-Prais & FD-OLS & P-FMOLS & P-DOLS & MG-FMOLS & MG-DOLS \\
\hline $\log A$ & $1.25 * *$ & $1.14 * *$ & $0.18 * *$ & $1.01 * *$ & $0.80 * *$ & $0.91 * *$ & $0.79 * *$ & $0.84 * *$ & $1.09 * *$ \\
\hline Log Pop & $1.11 * *$ & $1.87 * *$ & $0.29 * *$ & $1.10 * *$ & $1.73 * *$ & $1.23 * *$ & $1.14 * *$ & $1.11 * *$ & $1.91 * *$ \\
\hline Log IEI & $0.51 * *$ & $0.31 * *$ & $0.044 * *$ & $0.27 * *$ & $0.24 * *$ & $0.32 * *$ & $0.20 * *$ & $0.21 * *$ & $0.20 * *$ \\
\hline Log sh nff & $-0.11 * *$ & $-0.07 * *$ & $-0.02 * *$ & $-0.07 * *$ & $-0.07 * *$ & $-0.10 * *$ & $-0.08 * *$ & $-0.17 * *$ & $-0.21 * *$ \\
\hline LDV/AR & & & $0.86 * *$ & 0.98 & & & & & \\
\hline Obs & 3141 & 3141 & 3075 & 3141 & 3061 & 3061 & 2901 & 3061 & 2901 \\
\hline $\begin{array}{l}\text { Order of } \\
\text { integration }\end{array}$ & $\mathrm{I}(1)$ & $\mathrm{I}(1)$ & $\mathrm{I}(0)$ & $\mathrm{I}(1)$ & $\mathrm{I}(0)$ & $\mathrm{I}(1)$ & $\mathrm{I}(0)$ & $\mathrm{I}(1)$ & $\mathrm{I}(0)$ \\
\hline Mean rho & 0.54 & 0.45 & 0.16 & 0.54 & 0.14 & 0.51 & 0.21 & 0.51 & 0.15 \\
\hline CD (p) & $-3.7(0.00)$ & $-2.5(0.01)$ & $-2.3(0.02)$ & $-3.6(0.00)$ & $-2.2(0.03)$ & $6.5(0.00)$ & $5.3(0.00)$ & $4.2(0.00)$ & $1.8(0.07)$ \\
\hline
\end{tabular}

Notes: A is real GDP per capita; Pop is population; IEI is industry energy intensity; sh nff is share of nonfossil fuels in primary energy. LDV/AR refers to the coefficient for the lagged dependent variable or AR term. Obs is observations. ** indicates statistical significance at the $1 \%$ level.

Diagnostics: Order of integration of the residuals is determined from the Pesaran (2007) CIPS test: I(0)みstationary, I(1)み nonstationary. Mean rho is the mean absolute correlation coefficient of the residuals from the Pesaran (2004) CD test. CD is the test statistic from that test along with the corresponding p-value in parentheses. The null hypothesis is cross-sectional independence.

While all the estimated elasticities are apparently statistically significant and many are similar in magnitude, several of the estimators produced nonstationary residuals (surprisingly so for both FMOLS ones). Also, cross sectional independence in the residuals was rejected for all estimators (at least at the 10\% level); however, four estimators (2FE-LDV, FD-OLS, P-DOLS, and MG-DOLS) mitigated this correlation (as can be seen from relatively low mean rho statistics). 
Appendix D. Time span robustness of long-run affluence and population estimations. Aggregate carbon emissions dependent variable. Panel coefficients for population and affluence along with their $95 \%$ confidence intervals in brackets shown.

\begin{tabular}{|c|c|c|c|c|c|c|c|c|}
\hline \multirow{3}{*}{$\begin{array}{l}\text { Time } \\
\text { span }\end{array}$} & \multicolumn{4}{|c|}{ Non-OECD countries (45) } & \multicolumn{4}{|c|}{ OECD countries (25) } \\
\hline & \multicolumn{2}{|c|}{ CMG } & \multicolumn{2}{|c|}{ AMG } & \multicolumn{2}{|c|}{ CMG } & \multicolumn{2}{|c|}{ AMG } \\
\hline & $\log A$ & Log Pop & $\log A$ & Log Pop & $\log A$ & Log Pop & $\log A$ & Log Pop \\
\hline 1971- & 0.88 & 0.82 & 0.89 & 0.93 & 0.68 & 0.97 & 0.78 & 0.95 \\
\hline 1991 & [0.68 1.07] & [020 1.44] & {$[0.721 .06]$} & {$[0.641 .22]$} & {$[0.410 .93]$} & {$\left[\begin{array}{lll}-0.24 & 2.18\end{array}\right]$} & {$\left[\begin{array}{lll}0.63 & 0.92\end{array}\right]$} & {$\left[\begin{array}{ll}-0.35 & 2.25\end{array}\right]$} \\
\hline 1975- & 0.66 & 3.13 & 0.82 & 1.03 & 0.55 & 0.26 & 0.73 & 1.26 \\
\hline 1995 & {$[0.470 .85]$} & [0.002 6.26] & [0.62 1.01] & {$[0.701 .36]$} & {$\left[\begin{array}{lll}0.34 & 0.76\end{array}\right]$} & {$\left[\begin{array}{lll}-0.99 & 1.50\end{array}\right]$} & {$\left[\begin{array}{lllllll}0.59 & 0.88\end{array}\right]$} & {$\left[\begin{array}{lll}-0.08 & 2.59\end{array}\right]$} \\
\hline 1980- & 0.74 & -1.07 & 0.72 & 1.26 & 0.41 & 0.21 & 0.66 & 1.22 \\
\hline 2000 & {$\left[\begin{array}{lll}0.61 & 0.88\end{array}\right]$} & {$\left[\begin{array}{lll}-4.40 & 2.27]\end{array}\right.$} & {$\left[\begin{array}{lll}0.50 & 0.94\end{array}\right]$} & [0.58 1.05] & {$\left[\begin{array}{lll}0.13 & 0.69\end{array}\right]$} & {$\left[\begin{array}{ll}-1.72 & 2.15\end{array}\right]$} & {$\left[\begin{array}{lll}0.48 & 0.83\end{array}\right]$} & [0.27 2.18] \\
\hline 1990- & 0.86 & 0.80 & 0.82 & 1.65 & 0.52 & 0.28 & 0.64 & 1.00 \\
\hline 2011 & [0.64 1.07] & {$\left[\begin{array}{ll}-0.53 & 2.13\end{array}\right]$} & [0.58 1.05] & [1.35 1.95$]$ & {$[0.240 .81]$} & {$\left[\begin{array}{lll}-0.32 & 0.89\end{array}\right]$} & {$\left[\begin{array}{lll}0.50 & 0.78\end{array}\right]$} & [0.09 1.90] \\
\hline 1985- & 0.92 & 0.07 & 0.77 & 1.03 & 0.50 & -0.36 & 0.63 & 0.48 \\
\hline 2005 & [0.72 1.13] & {$\left[\begin{array}{lll}-1.40 & 1.53]\end{array}\right.$} & {$\left[\begin{array}{lll}0.60 & 0.94\end{array}\right]$} & [0.58 1.48] & {$[0.180 .82]$} & {$\left[\begin{array}{lll}-2.66 & 1.94\end{array}\right]$} & {$[0.440 .83]$} & {$\left[\begin{array}{ll}-0.23 & 1.19\end{array}\right]$} \\
\hline 1971- & 0.82 & 0.78 & 0.90 & 0.99 & 0.72 & 0.92 & 0.72 & 1.01 \\
\hline 1996 & [0.64 1.00] & {$\left[\begin{array}{lll}0.03 & 1.53\end{array}\right]$} & [0.71 1.09] & [0.64 1.33] & {$\left[\begin{array}{lll}0.53 & 0.91\end{array}\right]$} & {$\left[\begin{array}{lll}-0.005 & 1.85\end{array}\right]$} & {$\left[\begin{array}{lll}0.58 & 0.85\end{array}\right]$} & [0.15 1.86] \\
\hline 1975- & 0.78 & 1.55 & 0.88 & 1.21 & 0.51 & 0.53 & 0.65 & 1.63 \\
\hline 2000 & {$\left[\begin{array}{lll}0.60 & 0.97]\end{array}\right]$} & {$\left[\begin{array}{lll}-0.39 & 3.48\end{array}\right]$} & [0.66 1.09] & [0.88 1.54] & {$\left[\begin{array}{lll}0.31 & 0.70\end{array}\right]$} & {$\left[\begin{array}{lll}-0.46 & 1.54\end{array}\right]$} & {$\left[\begin{array}{lll}0.51 & 0.78\end{array}\right]$} & [0.34 2.92] \\
\hline 1980- & 0.85 & -0.002 & 0.91 & 1.27 & 0.44 & -0.08 & 0.64 & 0.69 \\
\hline 2005 & [0.68 1.02] & {$\left[\begin{array}{lll}-1.94 & 1.93\end{array}\right]$} & [0.72 1.11] & [0.96 1.59] & $0.200 .67]$ & {$\left[\begin{array}{lll}-1.68 & 1.52\end{array}\right]$} & {$\left[\begin{array}{lll}0.46 & 1.35\end{array}\right]$} & [0.02 1.35] \\
\hline 1985- & 1.04 & 0.56 & 0.81 & 1.34 & 0.55 & 0.01 & 0.65 & 0.62 \\
\hline 2011 & {$\left[\begin{array}{lll}0.81 & 1.27]\end{array}\right]$} & {$\left[\begin{array}{lll}-0.74 & 1.86\end{array}\right]$} & [0.64 0.98 ] & [1.07 1.64] & [0.27 0.84$]$ & {$\left[\begin{array}{lll}-0.74 & 0.76\end{array}\right]$} & {$\left[\begin{array}{lll}0.51 & 0.79\end{array}\right]$} & [0.003 1.24$]$ \\
\hline 1971- & 0.82 & 0.86 & 0.96 & 1.13 & 0.66 & 0.77 & 0.67 & 1.21 \\
\hline 2001 & [0.64 1.00] & {$\left[\begin{array}{ll}0.15 & 1.58\end{array}\right]$} & [0.78 1.14] & {$\left[\begin{array}{lll}0.80 & 1.45]\end{array}\right.$} & [0.45 0.87$]$ & {$\left[\begin{array}{lll}-0.19 & 1.74\end{array}\right]$} & {$\left[\begin{array}{ll}0.52 & 0.80\end{array}\right]$} & [0.12 2.30] \\
\hline 1975- & 0.90 & 1.03 & 0.97 & 1.20 & 0.51 & 0.76 & 0.68 & 1.10 \\
\hline 2005 & [0.75 1.06] & {$\left[\begin{array}{ll}-0.53 & 2.59\end{array}\right]$} & [0.81 1.13] & [0.92 1.48] & {$\left[\begin{array}{lll}0.30 & 0.72]\end{array}\right.$} & {$\left[\begin{array}{lll}-0.41 & 1.92\end{array}\right]$} & {$\left[\begin{array}{ll}0.53 & 0.83\end{array}\right]$} & [0.23 1.97] \\
\hline $1980-$ & 0.90 & 0.70 & 0.87 & 1.38 & 0.51 & 0.58 & 0.62 & 0.91 \\
\hline 2011 & [0.73 1.08] & {$\left[\begin{array}{lll}-0.59 & 1.99\end{array}\right]$} & [0.69 1.04] & [1.12 1.64] & {$\left[\begin{array}{lll}0.31 & 0.72\end{array}\right]$} & {$\left[\begin{array}{lll}-0.23 & 1.40\end{array}\right]$} & {$\left[\begin{array}{lll}0.46 & 0.78\end{array}\right]$} & [0.53 1.29] \\
\hline
\end{tabular}

Note: Only countries with data from 1971 were considered; the dropped countries were: Albania, Angola, Bulgaria, Ethiopia, Mozambique, Nigeria, Panama, Poland, Uruguay, and Vietnam. 